\title{
Improving the consent process for cataract surgery
}

This article was published in the following Dove Press journal:

Clinical Ophthalmology

\section{Saeed Azizi \\ Abdirahman Osman \\ Omer Ali}

Faculty of Medicine, St George's Hospital Medical School, London, UK

Correspondence: Saeed Azizi

Faculty of Medicine, St George's Hospital Medical School, Cranmer Terrace,

London SWI7 ORE, UK

Tel +44798520 I878

Email saeedazizi@doctors.org.uk

\section{Dear editor}

We read the article by Vo et $\mathrm{al}^{1}$ with great interest. Vo et al ${ }^{1}$ highlighted that multimedia can act as an adjunct for consenting patients for cataract surgery. The article further brings to light the importance of the consent process and how this may change in the future with further accessibility to multimedia.

A well-informed consent process has a wide array of benefits. Nonetheless, there is a need to address the time pressure faced by many clinicians. Nehme et $\mathrm{al}^{2}$ discuss how the conventional consent process is often limited to treatment options, technical aspects, and procedural risks, whereas, ideally, the entire surgical pathway should be discussed with the patient. There have been various interventions designed to improve the consent process: taking consent in the outpatient setting, additional information resources, and increasing the allocated time for the consent process. The study by Vo et al $^{1}$ demonstrated that utilizing multimedia in the consent process for cataract surgery can reduce time taken to obtain informed consent by approximately $50 \%$, while not being detrimental to patient's comprehension or satisfaction.

The use of multimedia in the consent process holds great promise. We hold the view that it may be possible to improve the efficacy of multimedia resources by implementing modern learning theories. This may be in the form of making the multimedia resources interactive, as done by Abujarad et al. ${ }^{3}$ Further consideration is required while utilizing these resources to ensure the consent process remains patient centered to minimize patient anxiety. Davidson et $\mathrm{al}^{4}$ discuss the benefits of patient-centered consultations; a focus on patient's satisfaction helped to address patient's concerns and alleviate their anxiety. In the systematic review by Nehme et al, ${ }^{2}$ nine of the 12 studies found no significant difference in the anxiety levels between patients who were consented with multimedia as an adjunct and those consented in the traditional manner. Lemon and Smith's ${ }^{5}$ study exploring the determinants of patient's satisfaction during consultations placed little significance on the consultation length but rather focused on the content of these consultations. While it is important to appreciate the systematic and individual benefits for reducing the length of preoperative assessment clinics, patient-centered care should remain priority. The needs of each patient differ; some require longer consultations, while others require a relatively shorter time with the physician. This approach allows health care professionals to tailor and optimize the preoperative workup to provide the best care possible.

We encourage an approach where the opportunity to engage with multimedia remains optional for patients. This provides the patient with educational resources as an optional adjunct; prioritizing the delivery of a more patient-centered care. We agree that, for the patient-doctor relationship to remain focal, further studies are 
required to establish the place of multimedia in preoperative clinics.

\section{Disclosure}

The authors report no conflicts of interest in this communication.

\section{References}

1. Vo T, Ngai P, Tao J. A randomized trial of multimedia-facilitated informed consent for cataract surgery. Clin Ophthalmol. 2018;12:1427-1432.
2. Nehme J, El-Khani U, Chow A, Hakky S, Ahmed AR, Purkayastha S. The Use of Multimedia Consent Programs for Surgical Procedures. Surg Innov. 2013;20(1):13-23.

3. Abujarad F, Alfano S, Bright TJ, et al. Building an Informed Consent Tool Starting with the Patient: The Patient-Centered Virtual Multimedia Interactive Informed Consent (VIC). AMIA Annu Symp Proc. 2017; 2017:374-383.

4. Davidson S, Mckendrick D, French T. Preassessment clinic interview and patient anxiety. Saudi J Anaesth. 2016;10(4):402-408.

5. Lemon TI, Smith RH. Consultation Content not Consultation Length Improves Patient Satisfaction. J Fam Med Prim Care. 2014;3(4): 333-339. 


\section{Authors' reply \\ Thomas A Vo \\ Philip Ngai \\ Jeremiah $\mathrm{P}$ Tao}

Department of Ophthalmology, Gavin Herbert Eye Institute, University of California Irvine School of Medicine, Irvine, CA, USA

Correspondence: Philip Ngai

Department of Ophthalmology, Gavin Herbert Eye Institute, University of California Irvine School of Medicine, 850 Health Sciences Road, Irvine, CA 92697-4375, USA

Tel +l 9498242020

Email pngai@uci.edu

\section{Dear editor}

We thank Dr Azizi and colleagues for showing interest in our article ${ }^{1}$ and for taking the time to provide us commentary feedback. While, in our study, it was observed that the utilization of multimedia resources reduced the consent process time for the clinic and, in particular, for the physician, the cumulative consent process time was overall extended for the patient. The benefit of the use of multimedia resources here, however, is that the physician face time becomes more meaningful. By establishing a proper and consistent baseline knowledge level regarding the surgical procedure, it enables a more impactful discussion that can be personalized to each individual patient's needs and concerns.
The authors would like to clarify that we agree that the use of a multimedia-facilitated informed consent process holds promise in improving the overall patient experience and that it should be implemented in a manner that maximizes benefit to the patient above all else. The purpose of our article ${ }^{1}$ is to highlight multimedia as an adjunct to enhance the experience of the consent process for the patient; however, we also felt it important to examine its impact on in-office discussion as well as on clinic and physician resources. These two points are not diametrically opposed in our opinion. As with Nehme et al, ${ }^{2}$ we observed positive benefits associated with multimedia use as an adjunct to conventional consent; however, we also agree that further studies are required to better establish the exact role that multimedia should have in the preoperative setting.

\section{Disclosure}

The authors report no conflicts of interest in this communication.

\section{References}

1. Vo TA, Ngai P, Tao JP. A randomized trial of multimedia-facilitated informed consent for cataract surgery. Clin Ophthalmol. 2018;12: $1427-1432$

2. Nehme J, El-Khani U, Chow A, Hakky S, Ahmed AR, Purkayastha S. The Use of Multimedia Consent Programs for Surgical Procedures. Surg Innov. 2013;20(1):13-23.

Dove Medical Press encourages responsible, free and frank academic debate. The content of the Clinical Ophthalmology 'letters to the editor' section does not necessarily represent the views of Dove Medical Press, its officers, agents, employees, related entities or the Clinical Ophthalmology editors. While all reasonable steps have been taken to confirm the content of each letter, Dove Medical Press accepts no liability in respect of the content of any letter, nor is it responsible for the content and accuracy of any letter to the editor.

\section{Publish your work in this journal}

Clinical Ophthalmology is an international, peer-reviewed journal covering all subspecialties within ophthalmology. Key topics include: Optometry; Visual science; Pharmacology and drug therapy in eye diseases; Basic Sciences; Primary and Secondary eye care; Patien Safety and Quality of Care Improvements. This journal is indexed on
PubMed Central and CAS, and is the official journal of The Society of Clinical Ophthalmology (SCO). The manuscript management system is completely online and includes a very quick and fair peer-review system, which is all easy to use. Visit http://www.dovepress.com/ testimonials.php to read real quotes from published authors. 